\title{
Performance Analysis of Combined Cycle Power Plant Using Multi-Effect Distillation (MED) Desalination Process
}

\author{
Geliş / Received: 12/05/2019
}

\author{
Oğuzhan ERBAŞ ${ }^{1 *}$
}

Revize / Revised: 29/05/2019

Kabul / Accepted: 30/05/2019

A

bstract- Water is the most important substance on earth. Seawater distillation processes have a considerable technique suitable for producing large scale quantities of potable water. This process involves a wide range of technologies that yield access to different sources of water such as seawater, ground and surface water, and wastewater. Because of the reduction in access to fresh water in recent decades and the uncertainty in availability effected by climate change, desalination is the critical process that ensure the future of humanity for fresh water requirement. Multi effect distillation process employs the same principles with multi-stage flash distillation but in contrasts, it occurs in a series of vessels (effects) and uses the principles of evaporation and condensation at reduced ambient pressure. A dual-purpose desalination plant has a process that produces both power and fresh water using optimum thermal energy. It offers a considerable saving in energy usage. This paper focuses on the modelling and thermodynamic analysis of the "Multi-Effect Distillation" (MED) desalination installed in combined cycle power plant and moreover the expected performance characteristics of the designed MED desalination plant has been determined.

Keywords- MED Desalination Process, Combined Cycle Power Plant, Performance Analysis

\section{I.INTRODUCTION}

The fact that the use of water resources has become increasingly limited has led to the use of alternative sources such as sea water for water supply. The rapid growth of the world population and the industrialization of societies continuously increase water consumption. Previously sufficient clean water resources have become insufficient. Especially in countries with dry climate, water shortage is larger. Processes aiming at obtaining water intended for drinking, watering and using by eliminating the salt, minerals and other impurities present in the water are generally called desalination processes $[1,3]$.

Desalination plants are processes that produce fresh water from salt water. Thermal or membrane processes are generally used in these facilities. Thermal processes are based on the evaporation and condensation of salt water. Desalination, suitable for industrial or domestic use, for the purpose of producing clean water from salty groundwater or sea water from the process of removal of water and other minerals. In 1978, the first seawater desalination plant was established in Jeddah, Saudi Arabia. As the type of desalination technology affects the amount and quality of the required feed water as well as the intense salty sea water (discharged seawater) components and discharge rate, it is important that the marine and coastal engineers understand the different desalination technologies [2].

Today, there are two main technologies used in desalination processes. These are thermal and membrane technologies. Thermal methods include heating the sea water to produce water vapor which will then condense and produce fresh water. During this process, intense saline sea water flow is produced which must be discharged. Membrane technologies enable the membranes to be used in two commercial desalination processes such as electro dialysis and reverse osmosis to remove salt from sea water. The membrane is a flat surface with selective permeability separating salt and other impurities from seawater.

${ }_{1 *}^{*}$ Corresponding Author: oguzhan.erbas@dpu.edu.tr (https://orcid.org/0000-0001-9424-4273)

Department of Mechanical Engineering, Kutahya Dumlupinar Univ. Evliya Celebi Campus, Kutahya, Turkey. 
Hybrid desalination methods are the facilities where the desalinize water requirement is operated by providing thermal and membrane facilities together. Combined heat and power plant installations are used to generate power, and the energy source is then used to desalinate seawater through thermal processes in general. In addition to the cooling water, the inlet port also provides the supply of feed water for the desalination process. These systems have enormous economic benefits because of the fact that energy is the largest operating cost in any desalination process and the fuel consumption is significantly lower in these dual-purpose plants compared to two separate facilities. However, the units are permanently connected and therefore cannot display the desalination plant function if the turbine is not running for maintenance or similar reasons [5].

The most used membrane process in desalination plants is reverse osmosis. With reverse osmosis process operated desalination systems consist of three stages. These are pre-treatment, membrane system and final refining. Water taken with suitable water intake structure first they are being treated. Reverse osmosis membranes are operated at high pressure and cost high materials are pre-treatment of raw water for passing provides the long-term use of reverse osmosis membranes and hinders potential operating problems. It can be used for human consumption purposes because it provides $99 \%$ ion removal. In order to be absolutely conditioned and with free chlorine they must be disinfected. Water intake structures are an important element of reverse osmosis desalination systems. Water should be supplied at stable flow and quality throughout the life of a membrane plant. Water intake structures from sea water are in two forms. The first one is the surface water intake structures, and the second one is the water intake structures. Submersible dewatering structures are used especially in small and medium sized seawater treatment plants. Large capacity reverse seawater purifier osmosis systems use more open water intake structures [6].

Power plants, cooling water purpose use sea water. The reverse osmosis plant is used as cooling water and used as water as raw water and used to be discharged. Hence, the reverse osmosis plant anchorage pipe is connected to the cooling water discharge line and there is no need to construct a separate line. The concentrate flow from desalination is connected to the cooling water discharge line from the bottom of the dewatering line taken to the desalination system. In reverse osmosis desalination systems, pre-treatment systems come after water intake structure. Prior to the reverse osmosis membrane, cartridge filters are used to prevent blockages of the membranes by particulate matter. Material selection in reverse osmosis systems so that the selected material is not damaged by corrosion it is important. In sea water reverse osmosis systems, they usually use duplex stainless steel for high pressure piping. Some inhibitors of reverse osmosis-treated water may also be added to prevent water corrosion. Phosphate and silica inhibitors can shrink tubing and reduce corrosion. Control and automation units are very important units in water treatment systems and especially in advanced treatment systems such as membrane processes. When deciding on reverse osmosis system, other water supply systems (inter-water transfer, wastewater recovery, etc.) should be compared with the long-term plan to work and according to the appropriate method should be preferred $[4,6]$.

\section{II.MULTI-EFFECT DISTILLATION (MED) METHOD}

A thermal method encountered in practice is a Multi-Effect Distillation (MED) method. In this method, the steam produced by a unit is concentrated at a lower temperature and pressure in the next unit; this also provides additional heat for evaporation. Compared to the MSF technology, the MED technology does not require additional heat for evaporation at all levels and is operated at lower temperatures $\left(\sim 70^{\circ} \mathrm{C}\right)$ than $\mathrm{MSF}$.

In a MED plant, seawater taken into the system is first processed and sprayed on the tubes where the pre-heated water vapor passes. That is, it is distributed over the surface of the evaporator tubes in a thin film to support sudden evaporation. The resulting water vapor passes to the second process and is concentrated by heat transfer. Evaporators are placed in series. Feed water is pumped and evaporated in the first section. The steam is then transported and used as thermal energy for evaporation in the next section where some of the remaining feed water is evaporated. This event continues as a sequential process. In the first process, only a portion of the seawater coming into the tubes is evaporated and the remaining seawater is fed into the second process. Fig. 1 shows Simplified scheme of a MED process [7]. 


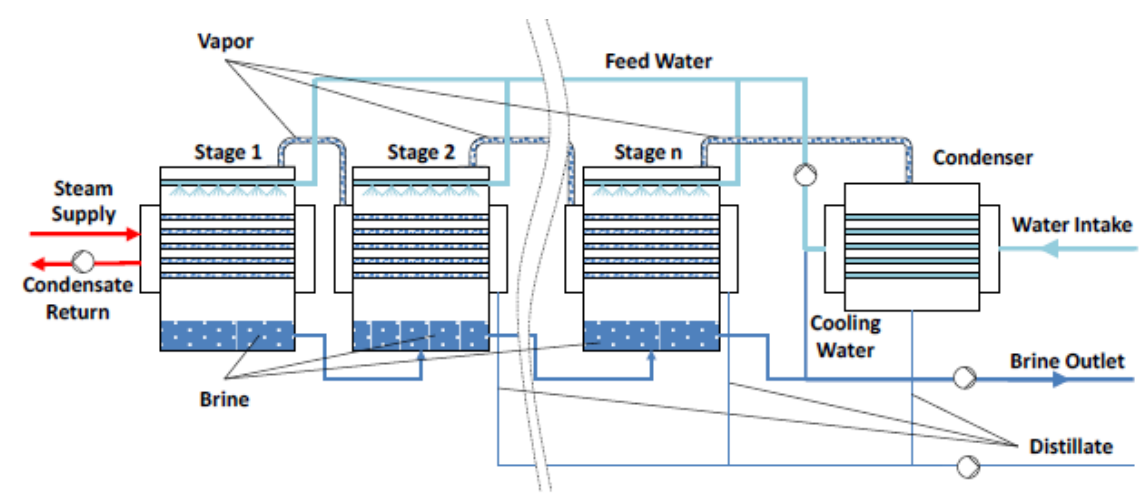

Figure 1. Simplified scheme of a MED process

These tubes are heated by the vapors created in the first process, respectively. This steam is used to vaporize a portion of the seawater supply remaining in the next process, while the other part is condensed for fresh water production and this process continues sequentially. Three arrangements have evolved for MED processes. They are based primarily on the arrangement of the heat exchanger tubing; horizontal tube arrangement, vertical tube arrangement and vertically stacked tube bundles. If the feed water is taken from an offshore inlet, the feed water is transferred to the land via a tunnel or pipeline from the seawater inlet port. The sea water flow is transferred through the main discharge line through the emitter. The development of marine environment life in the sea water inlet can have a great impact on the hydraulics and operation of the desalination plant. Therefore, pipe material should be considered as durable as HDPE against marine environment life [5,7].

However, the most optimal model was chosen; the pipeline's project life, pipeline cost, special financial requirements and local support, financial issues, design flow, hydraulic losses and appropriate reduction (pump or gravity) based on the necessary internal diameter, pipeline installation, international acceptance, long-term external and internal criteria such as protection requirements, maintenance, testing methods should be considered. During the desalination process, heavy metals such as copper, lead and iron may also be mixed into the dense salt water. This may be due to the corrosion of the desalination equipment or the can be welded. The environmental impact of dense salt seawater removal can be reduced by hand-made or natural filtration processes, reducing the amount of chemicals applied during pre-treatment. For example, ultrafiltration, which removes silt and organic matter from feed water, can replace coagulants. In all these areas, it is considered to be a good economic alternative by hybrid desalting, which combines thermal and membrane desalination processes. Hybrid configurations are available in operation with ease, convenience, flexibility, low energy consumption, remote construction work, high plant area, better power and convenient water.

\section{III.ANALYSIS OF COMBINED CYCLE POWER PLANT WITH MULTI-EFFECT DISTILLATION (MED)}

The main purpose of the combined cycle power plants is to generate electricity using the waste heat gases and to increase the efficiency. Gas plants alone their yields are low but their yields are increased when combined cycle. Contribution to national economy it is provided. Gas turbines and steam turbines are used together in combined cycle power plants. In addition to the electrical energy obtained from gas turbines using natural gas as fuel, the steam obtained from the steam turbines and the steam obtained from the steam turbines which are produced by transferring the waste heat of the exhaust gases with high temperature from the turbine exhaust. Combined cycle power plants offer high efficiency and power as well as adaptable to flexible operating conditions, quick commissioning and easy adaptation to full load and variable load situations. They also have high efficiency in variable load conditions [4].

A co-generation plant, which produces both electricity and good quality water, is often called a dualpurpose plant. A dual-purpose desalination plant is a process that produces both power and desalted water with the optimum use of thermal energy in producing the two products. It offers a considerable saving in energy usage. For example a single-purpose power plant producing electrical production of water and power [8]. In particular, it is desirable to operate a power plant near base load to be most economic. In parallel co-generation, electricity is produced as co-product along with desalted water by diverting part of the steam to the turbine to produce electricity and part of the steam to the desalination plant. This configuration allows increased flexibility in energy usage [7]. 
This study demonstrates coupling of a combined cycle plant and an MED desalination plant (Figure 2). The desalination plant (12 MIGD) is modelled by a Thermoflow (Thermal Engineering Software). In this study, HRSG is sized at $33{ }^{\circ} \mathrm{C}$ degree ambient, MED desalination plant is sized at $28{ }^{\circ} \mathrm{C}$ degree seawater. In order to run the desalination plant at variable load and maintained LPT at the same extraction pressure, LPT is sized at the maximum through flow.

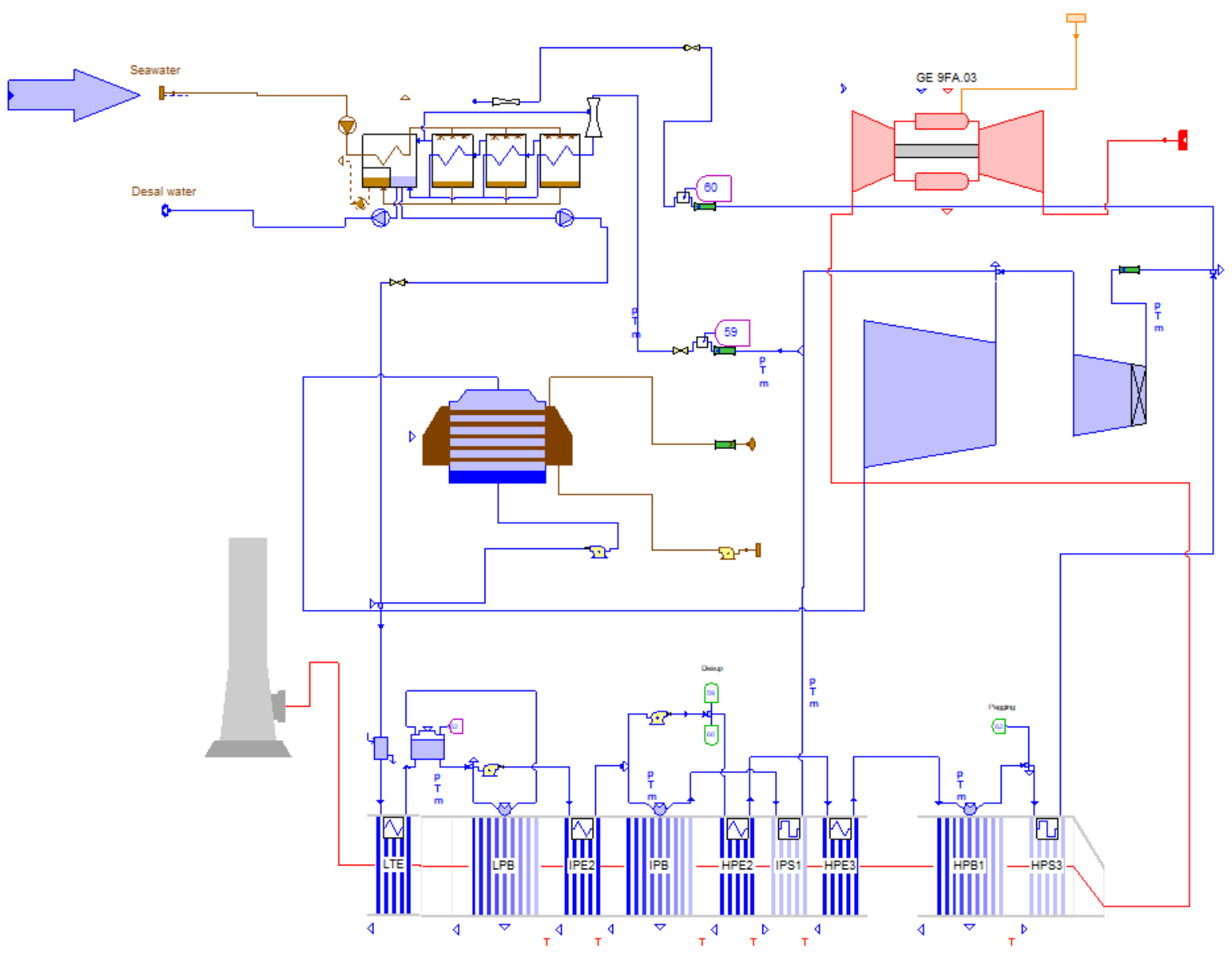

Figure 2. Combined cycle power plant with distillation process

In the MED process, sea water is sprayed onto horizontal tubes passing the water vapour in the form of a thin film to form a spray. The thin film layer outside the tube condenses into the vapour inside the tube as the water evaporates. The non-volatile portion of the seawater in the first process is fed into the second process in such a way that a thin film layer is formed again. The process usually has 8-16 processors. The process is operated between $65-70{ }^{\circ} \mathrm{C}$. In the desalination plant, energy, membrane, wear, chemicals and maintenance are the main costs. For the real scale design of membrane processes, input water quality values, target effluent quality values, percentage of retention of the pollutants in the membrane (rejection), water recovery rate, water flux, and drive power (pressure difference) values should be known. Figure 3. shows Multi-Effect Distilation (MED) desalination cycle schematic. 


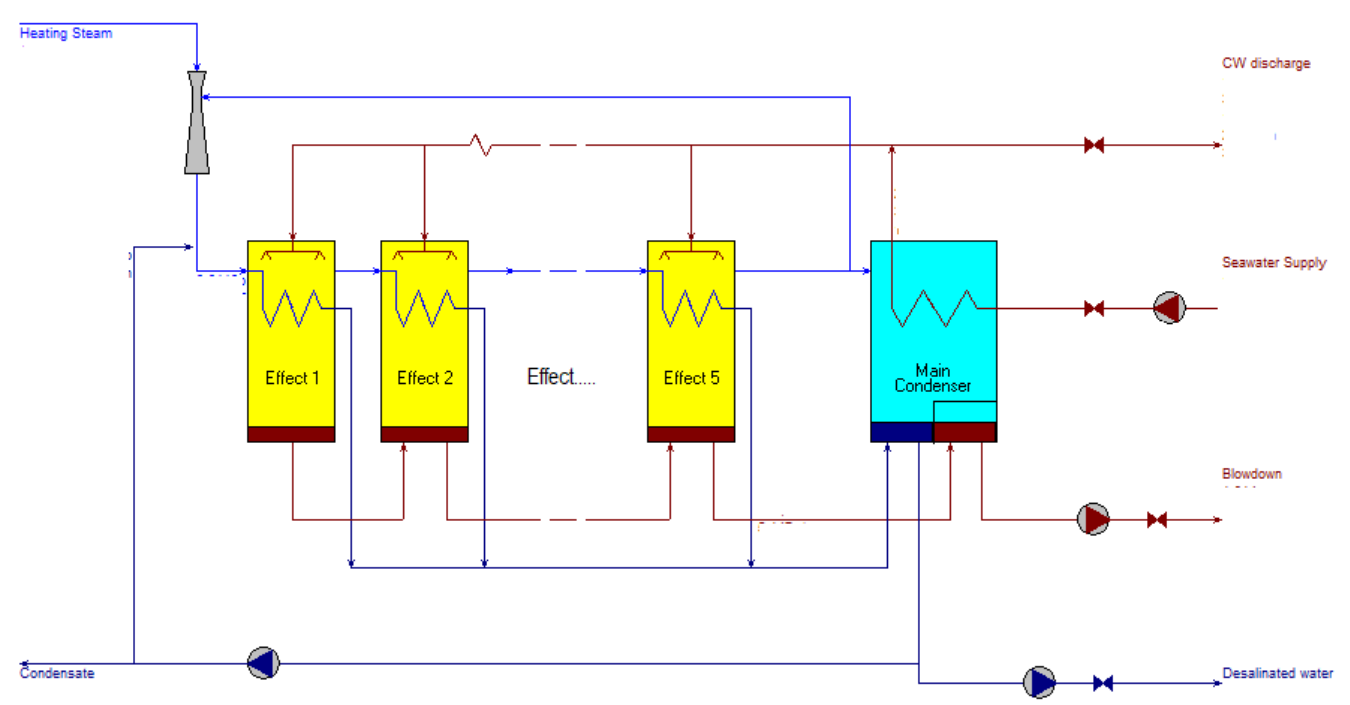

Figure 3. Multi-effect distilation (MED) desalination cycle schematic

\section{IV.CONCLUSIONS}

Water quality is a serious concern for a number of reasons. Due to unplanned and rapid urbanization, excessive use of natural resources, untreated industrial and domestic wastewater discharge into fresh water sources and into the sea, inadequate wastewater treatment plants and non-point agricultural pollution are among these reasons. Significant efforts are made to increase the wastewater collection and treatment capacity for people living in large cities. In the world and in our country, the depletion of water resources and the availability of existing water resources make the issue of water supply more prominent. The salt content from the sea to the sea varies greatly. Salinity generally increases as the depth increases in seas, but this increase is not much. Density of sea water changes depending on pressure, salinity and water temperature.

Depending on the flow of fresh water to the sea, the salt content may be high or low. The main salts of sea water are salt, chlorine, sodium, sulphates, magnesium, calcium, potassium, bicarbonate and bromine. Desulfurization involves the removal of salts and biological materials from sea water to obtain fresh water. Multi-process distillation has long been used for industrial distillation. In the MED process, high heat transfer rates can be obtained depending on the thin film boiling and condensation conditions. At the same time evaporation occurs at a uniform temperature at each effect. MED facilities that use polymer doped sediment control are usually made for low temperature operation. Table 1. shows plant summary and heat balance results.

Table 1. Combined cycle plant design results

\begin{tabular}{|l|c|c|}
\hline Plant Summary (Heat Balance Results) \\
\hline Ambient pressure & bar & 1,038 \\
\hline Ambient temperature & ${ }^{0} \mathrm{C}$ & 33 \\
\hline Ambient RH & $\%$ & 74 \\
\hline Gross electric efficiency(LHV) & $\%$ & 45,15 \\
\hline Gross heat rate(LHV) & $\mathrm{kJ} / \mathrm{kWh}$ & 6895 \\
\hline Net electric efficiency(LHV) & $\%$ & 43,88 \\
\hline Net heat rate(LHV) & $\mathrm{kJ} / \mathrm{kWh}$ & 7180 \\
\hline Net electric efficiency(HHV) & $\%$ & 38,96 \\
\hline Net heat rate(HHV) & $\mathrm{kJ} / \mathrm{kWh}$ & 8186 \\
\hline Desalinated Water & $\mathrm{kg} / \mathrm{s}$ & 189,8 \\
\hline Mass flow (per unit) & $\mathrm{MIGD}$ & 12 \\
\hline Volume flow (total, MIGD) & $\mathrm{m} / \mathrm{day}$ & 51156 \\
\hline Volume flow (m $3 / \mathrm{day}$ per unit) & $\%$ & 3,22 \\
\hline Seawater Discharge & $\mathrm{kg} / \mathrm{s}$ & 2482 \\
\hline Salinity & \\
\hline Mass flow (per unit) &
\end{tabular}


As spongy particle cleaning cannot be performed, acid cleaning should be done more frequently than MSF process. In large capacity plants, it is seen that thermal methods are more economical in terms of operation and investment, especially in regions where energy is cheap, large capacity desalination plants are more economical. Small-capacity membrane filtration methods are more economical in terms of operating and investment costs from thermal systems in terms of both economic and flexible use. In the desalination plant, investment, operating costs and plant capacity are important for process selection. The first object in the process design is to minimize investment costs and thus reduce the amount of thermal and mechanical energy need, equipment and materials required for construction. Modules and other parts of the plant must have structural requirements. Pre-treatment of seawater is essential for this method to be used without any obstacles.

\section{REFERENCES}

[1] Mohamed, E.S., Boutikos, P.,Mathioulakis,E., Belessiotis,V.,(2017).Experimental evaluation of the performance and energy efficiency of a Vacuum Multi-Effect Membrane Distillation system, Desalination, 408, pp. 70-80

[2] Chacartegui, R., Sanchez, D., Di Gregorio, N., Jiménez-Espadafor, F. J., Munoz, A., \& Sanchez, T., (2009). Feasibility analysis of a MED desalination plant in a combined cycle based cogeneration facility, Applied thermal engineering, 29(2-3), 412-417.

[3] Almutairi, A., Pilidis, P., Al-Mutawa, N., \& Al-Weshahi, M. (2016).Energetic and exergetic analysis of cogeneration power combined cycle and ME-TVC-MED water desalination plant: Part-1 operation and performance, Applied Thermal Engineering, 103, 77-91.

[4] Sayyaadi, H., \& Saffari, A. (2010).Thermoeconomic optimization of multi effect distillation desalination systems, Applied Energy, 87(4), 1122-1133.

[5] Hosseini, S. R., Amidpour, M., \& Shakib, S. E., (2012). Cost optimization of a combined power and water desalination plant with exergetic, environment and reliability consideration, Desalination, 285, 123-130.

[6] Voutchkov,N., (2013). Desalination Engineering: Planning and Design 1st Edition, McGraw-Hill Education, 1 edition, New York.

[7] Sommariva, C., (2010). Desalination and Advanced Water Treatment Economics and Financing, Balaban Desalination Publications, Rome - Italy.

[8] Al-Mutaz, I., Al-Namlah, A., (2004). Characteristics of dual purpose MSF desalination plants, Desalination,166,287-294. 